\title{
Os educadores na educação do campo e as suas condições de trabalho docente
}

Loriége Pessoa Bitencourt ${ }^{1}$, Laudemir Luiz Zart ${ }^{2}$

${ }^{1}$ Universidade do Estado de Mato Grosso - UNEMAT. Programa de Pós-Graduação em Educação. Avenida Santos Dumont, s/n - Cidade Universitária. Cáceres - MT. Brasil. lori.pessoa@ hotmail.com. ${ }^{2}$ Universidade do Estado de Mato Grosso - UNEMAT

RESUMO. Este artigo tem como objetivo refletir sobre os docentes da Educação do Campo de uma escola da região de Fronteira Brasil-Bolívia e as suas condições de trabalho para realização de práticas pedagógicas adequadas a essa modalidade de educação. Tais docentes compõem um grupo de profissionais da educação que atuava no ano de 2015 na Escola Estadual 12 de Outubro, situada a, aproximadamente, 90 quilômetros de Cáceres/MT. Buscou-se compreender os desafios anunciados pelos educadores para o seu trabalho docente na Educação do Campo. A questão problema que nos orientou foi: quem são os educadores de uma escola do campo e quais são os desafios elencados por eles para o desenvolvimento de seu trabalho docente cotidiano? Tratou-se de uma pesquisa qualitativa que teve como lócus a escola citada, no ano de 2015, no âmbito do Projeto Sala de Educador da referida Escola e, como sujeitos, os educadores que participaram da formação continuada desenvolvida pela equipe do Núcleo Unemat-Unitrabalho. Utilizou-se, para coleta de dados, entrevistas com um grupo de educadores, questionários e observações das atividades desenvolvidas.

Palavras-chave: Formação Continuada, Trabalho Docente, Educação do Campo. 


\title{
The educators in education of countryside and their conditions of teaching
}

\begin{abstract}
This article has as objective to reflect on the teachers of the Education of countryside of a school in the frontier region of Brazil-Bolívia and their working conditions to carry out of teaching work out pedagogical practices appropriate to this type of education. These teachers make up a group of education professionals who worked in the year 2015 at the State School 12 de Outubro, located, approximately, 90 kilometers from Cáceres/MT. It was sought to understand the challenges announced by the educators for their teaching work in education of countryside. The problem question that guided us was: who are the educators of a country school and what are the challenges listed by them for the development of their daily teaching work? It was a qualitative research that had as locus the mentioned school, in the year of 2015, within the scope of the Educator's Room of the said School and as subjects the educators who participated in the continuous formation developed by the team of the Nucleus Unemat-Unitrabalho. Interviews with a group of educators, questionnaires and observations of the activities developed.
\end{abstract}

Keywords: Continued Formation, Teaching Work, Education of Countryside. 


\title{
Los educadores en la educación de campo y sus condiciones de trabajo docente
}

\begin{abstract}
RESUMEN. Este artículo tiene como objetivo reflexionar sobre los docentes que trabajan en la educación de campo en una escuela de la región de frontera Brasil-Bolívia y sus condiciones de trabajo docente para la realización de prácticas pedagógicas adecuadas a esa modalidad de educación. Los docentes a quienes nos referimos componen un grupo de profesionales de la educación que actuaba en el año de 2015 en la Escuela Estatal 12 de Outubro, que está localizada a 90 kilómetros de Cáceres/MT. Él trató de comprender los desafíos anunciados por los educadores en su trabajo docente en la educación de campo. El problema que nos oriento fue: ¿Quiénes son los educadores de la escuela de campo y cuáles son los desafíos enfrentados por ellos para el desarrollo de su trabajo docente en la cotidianidad? Se trato de una investigación cualitativa que tuvo como locus la escuela ya citada, en el año 2015, en el ámbito del Proyecto Sala de Educador de esta escuela y como sujetos los educadores que participado de la formación continuada desarrollada por el equipo del Núcleo Unemat-Unitrabalho. Se utilizo para la recolección de los datos, entrevistas con un grupo de educadores, cuestionarios y observaciones de las actividades realizadas.
\end{abstract}

Palavras-clave: Formación Continuada, Trabajo Docente, Educación de Campo. 


\section{Introdução}

Há alguns anos a Educação do Campo tem sido umas das temáticas de discussões e reflexões baseadas em pesquisas e extensões que fundamentam as ações realizadas pela equipe do Núcleo Unemat-Unitrabalho, da Universidade do Estado de Mato Grosso. Partimos do pressuposto que

\begin{abstract}
A Educação do Campo é uma área de conhecimento que está associada à possibilidade de implementações de proposições instituídas de princípios políticos, pedagógicos e didáticos sobre o saber inerente as áreas de conhecimentos. Prima por uma educação voltada à realidade dos sujeitos do campo e a formação de professores-educadores aptos para atuarem nessas escolas, além da formação docente, que habilite $o$ docente a trabalhar os conteúdos e construir currículos que atendam as demandas pedagógicas do Ensino Fundamental e Ensino Médio. (Gaia \& Pires, 2016, p. 4).
\end{abstract}

Assim, considerando a Educação do Campo como uma área do conhecimento que necessita de aprofundamento teórico e prático para melhor compreendê-la, nossas ações voltam-se à compreensão da docência da Educação do Campo contextualizada a partir da realidade vivida em cada comunidade, assentamento, escola, com sujeitos singulares que a realizam e a experienciam. Para isso, buscamos analisar a constituição de identidade e práticas pedagógicas dos sujeitos protagonistas desta modalidade de Educação, com todas as suas características e princípios. Desse modo, faz-se importante, para a estruturação de todas as ações do núcleo, os princípios da Educação do Campo, expostos por Gaia e Pires (2016), pois norteiam nossas ações, desde o planejamento ao desenvolvimento das formações com os sujeitos do campo, sejam os da escola ou os das comunidades, de forma a evidenciar sua identidade, história, trabalho e a suas práticas cotidianas.

Nesse contexto, realizamos dois projetos que trataram especificamente da Educação do Campo: o Projeto de Extensão "Educação do Campo: Currículo, Formação de Professores, Docência, e Pedagogia da Alternância", em que desenvolvemos formação continuada para profissionais das escolas do campo; e o Projeto de Pesquisa “A Docência da Educação do Campo: análise da constituição de identidades e práticas pedagógicas", que nos permitem realizar formações continuadas com suporte da extensão universitária e, pois meio dela, efetuar pesquisa, coletando dados que nos permitam compreender o que é ser educador da Educação do Campo e como o docente descreve o seu trabalho, 
configurando suas práticas pedagógicas nessa modalidade de ensino.

A partir dessas ações, elaboramos este artigo que tem como objetivo compreender o ser educador na Educação do Campo, os desafios anunciados por eles para o desenvolvimento de seu trabalho docente cotidiano na Educação do Campo, em uma escola da rede estadual da região de Fronteira Brasil-Bolívia, Cáceres, Estado de Mato Grosso. A formação continuada que nos deu suporte para a pesquisa foi realizada na Escola Estadual 12 de Outubro, no ano de 2015, no âmbito do Projeto Sala de Educador da referida Escola.

O Projeto Sala de Educador ${ }^{\mathrm{i}}$ da Escola Estadual 12 de Outubro (PSE, 2015) teve como temática central: "Reflexão sobre a Prática Pedagógica" e foi composto por 10 (dez) oficinas, de 08 (oito) horas cada, oferecidas mensalmente no espaço da escola, para todos os profissionais da educação nela lotados, considerados como sujeitos pedagógicos responsáveis em diferentes funções pelo fazer educacional cotidiano, dentro ou fora da sala de aula, tais como: docentes, técnicos administrativos, técnicos de apoio, nutrição, motorista, vigilantes e gestores (a Diretora e Coordenadora Pedagógica).

É importante destacar que compreendemos como 'educador' todo aquele que concebe a escola, seus sujeitos e o currículo como meio, ela educa em interação entre conhecimento científico/formal e a realidade no contexto de vida dos sujeitos. Tem por objetivo a formação integral, humana e cidadã. Devido a isso, o educador questiona quais conhecimentos e ensino são adequados e relevantes para essa formação, sendo responsável pela formação educacional e social de crianças, jovens e adultos os preparando para o bem viver (Fiorentini \& Lorenzato, 2001). Assim, apesar de realizar a formação com todos os profissionais da educação, ou seja, todos aqueles considerados educadores, neste artigo, estaremos preocupados em analisar o trabalho dos docentes.

Desse modo, compreendemos a docência como "uma forma particular de trabalho sobre o humano, ou seja, uma atividade em que o trabalhador se dedica ao seu "objeto" de trabalho, que é justamente um outro ser humano, no modo fundamental da interação humana". (Tardif \& Lessard, 2005, p. 8). Isto é, a docência é o trabalho, são as atividades cotidianas que fazem parte da profisssão, é uma profissão de interações humanas, entre professores com os alunos e os outros "atores escolares" (Tardif \& Lessard, 2005), entre seus pares e com eles realizando o fazer escolar cotidiano. 
Neste sentido, Tardif e Lessard (2005) salientam que a "docência, enquanto trabalho de interações, apresenta ela mesma alguns traços particulares que estruturam o processo de trabalho cotidiano no interior da organização escolar". (Tardif \& Lessard, 2005, p. 11), por essa razão, é situada historicamente, contextualizada e vai além das atividades individualizadas que o professor costuma efetuar. Também alertam para a importância de se pensar o trabalho docente a partir da organização do trabalho em âmbito escolar, ou seja, enquanto divisão do trabalho, classes fechadas, seriadas, multiseriadas, ao isolamento dos professores, burocracia envolvida, etc. Afirmam, ainda, que os professores, com seus afazeres diários, sentem-se afetados individualmente enquanto pessoas, refletindo também no desenvolvimento de suas atividades. Assim, faz-se necessário analisar o trabalho docente de modo a "avaliar o trabalho escolar como um sistema de práticas coletivas e um processo total de transformações das crianças em adultos instruídos, socializados, educados, cultivados, etc". (Tardif \& Lessard, 2005, p. 12).

Concordamos com Tardif e Lessard (2005) quando afirmam que:

a escolarização repousa basicamente sobre interações cotidanas entre os professores e os alunos. Sem essas interações a escola não é nada mais que uma imensa concha vazia. Mas essas interações não acontecem de qualquer forma: ao contrário, elas formam raízes e se estruturam no âmbito do processo de trabalho escolar e, principalmente, do trabalho dos professores sobre e com os alunos. (p. 23).

Dessa forma, compreender a escola enquanto instituição profissional dos educadores, com suas características organizacionais e estruturais e quem são os educadores, nos auxiliam a entender o trabalho dos docentes e as possibilidades de práticas pedagógicas que gerem aprendizagens significativas e adequadas aos alunos.

Assim, para compreender quem são os educadores (docentes) e o seu trabalho, fez-se oportuno à oficina desenvolvida pela equipe do Núcleo Unemat-Unitrabalho, que nos ajudou a entender a realidade da Escola já mencionada e traçar o perfil de seus educadores e a configuração do trabalho docente desenvolvido no dia a dia educacional, constituído por práticas pedagógicas em uma escola que se denomina como do Campo. Para isso, a questão problema que nos orientou foi: quem são os educadores da escola do campo e quais são os desafios elencados por eles para o desenvolvimento de seu trabalho docente cotidiano? 


\section{A Escola enquanto infraestrutura física e humana: o lócus do trabalho docente}

A Escola Estadual 12 de Outubro ${ }^{\text {ii }}$ foi criada pelo Decreto n. ${ }^{\circ} 1.753$ de 29 de abril de 2003, publicado no Diário Oficial de 29/04/2013 e, após uma década de espera, iniciou suas atividades em Fevereiro de 2014. É considerada pela Secretaria Estadual de Educação (SEDUCMT) como uma escola da zona rural, do campo. É a única instituição educacional da região da Fronteira Brasil-Bolívia, ligada à rede estadual de ensino que oferece turmas dos três anos do Ensino Médio e turmas na modalidade de Educação de Jovens e Adultos (EJA).

Em 2015 contava com 47 (quarenta e sete) funcionários, dentre eles, 30 (trinta) docentes ${ }^{\text {iii }}$. Havia 239 (duzentos e trinta e nove) alunos matriculados no Ensino Médio, 138 (cento e trinta e oito) alunos matriculados na EJA - Fundamental I e 96 (noventa e seis) alunos matriculados na EJA - Médio ${ }^{\text {iv }}$, totalizando 491 (quatrocentos e noventa e um) alunos matriculados no ano considerado. Para atender todo esse público, oferta turmas nos três turnos e em diferentes espaços educacionais (na sede e em salas anexas nas dependências de outras instituições escolares).

Conforme o Projeto Político Pedagógico (PPP) da Escola, no ano de 2015, além das turmas de Ensino Médio organizadas por ano, isto é, turmas do $1^{\circ}$, $2^{\circ}$ e $3^{\circ}$ anos que eram ofertadas nas dependências da escola, em sua sede, também oferecia outras turmas de Ensino Médio em salas anexas (no espaço das escolas municipais da região) para atender os jovens e adultos que residem em outras localidades, conforme quadro a seguir:

Quadro 1 - Distribuição das Turmas de Ensino Médio e EJA.

\begin{tabular}{|l|l|c|c|}
\hline \multicolumn{1}{|c|}{$\begin{array}{c}\text { Localidade/comunidade de } \\
\text { Funcionamento das Salas Anexas }\end{array}$} & Turmas/Anos & $\begin{array}{c}\text { Formas de } \\
\text { funcionamento do } \\
\text { Ensino Médio }\end{array}$ & $\begin{array}{c}\text { Formas de } \\
\text { funcionamento } \\
\text { do EJA }\end{array}$ \\
\hline Sede - Escola Estadual 12 de Outubro & $1^{\circ}, 2^{\circ}$ e $3^{\circ}$ ano & Seriado (turmas) & EJA - Médio \\
\hline $\begin{array}{l}\text { Núcleo do Limão - Escola Municipal Santa } \\
\text { Catarina }\end{array}$ & $\begin{array}{l}1^{\circ}, 2^{\circ} \text { e } 3^{\circ} \\
\text { ano. }\end{array}$ & Seriado (turmas) & - \\
\hline Fazenda Soteco & $1^{\circ}, 2^{\circ}$ e $3^{\circ}$ ano & Multisseriado (turmas) & - \\
\hline Escola Municipal Clarinópolis & $1^{\circ}, 2^{\circ}$ e $3^{\circ}$ ano & Seriado & - \\
\hline
\end{tabular}

(Fonte: a partir do Projeto Sala de Educador (PSE) Escola 12 de Outubro do ano de 2015).

Como se observa no Quadro 1, a escola se organiza de forma mista, com turmas regulares/seriadas do Ensino Médio e turmas da EJA-Médio, ofertadas na sede da escola e turmas do Ensino Médio que funcionam em outras localidades, de forma seriada ou multiseriada, a fim de respeitar o local de residência dos alunos, levando 
os professores a se deslocarem de uma localidade à outra para realizar o seu trabalho cotidiano. Segundo do PSE (2015, p. 3):

Os alunos que pertencem a estas escolas são provenientes de 12 comunidades circunvizinhas formadas na grande maioria por assentamentos. As famílias são formadas por pequenos agricultores que vivem também do gado leiteiro. Nota-se na região a influência da cultura boliviana no cotidiano dessas famílias uma vez que as comunidades, em sua maioria, estão localizadas em áreas de fronteira.

Dessa forma, os alunos matriculados são distribuídos em quatro diferentes espaços, contando com a infraestrutura das escolas municipais para a oferta de salas anexas. Toda essa estrutura é gestada pela mesma diretora e coordenadora pedagógica, que fazem o trabalho administrativo e pedagógico a partir da sede da Escola Estadual 12 de Outubro e se deslocam, quando necessário, a essas outras localidades. No entanto, os docentes se deslocam diariamente e organizam seu horário de trabalho semanal levando em consideração esses deslocamentos.

Nesse sentido, da organização do trabalho e da profissionalização docente, Tardif e Lessard (2005) chamam a atenção quanto à própria estruturação das organizações escolares, pois afirmam que ela pouco se presta a
... uma profissionalização séria desse ofício: fechados em suas classes, os professores não têm nenhum controle sobre o que acontece fora dela; eles privilegiam, consequentemente, práticas marcadas pelo individualismo, ausência de colegialidade, o recurso à experiência pessoal como critério de competência, etc. Em suma, longe de estar se profissionalizando, constatase que esses diferentes fatos levantam no fundo toda a questão da proletarização do trabalho docente ou, ao menos, da transformação de grupos de professores em equipes de executivos que não têm nenhum vínculo com a decisões que os afetam. (p. 27).

Destacamos, ainda que, no caso dos educadores da Escola Estadual 12 de Outubro, todos são lotados nesta escola. No entanto, a maioria deles distribui sua carga horária de trabalho semanal e organiza o seu trabalho em diferentes localidades, entre a sede e/ou nas salas anexas (extensões da Escola em outras localidades). Assim, nem sempre convivem e interagem com o mesmo grupo de trabalho, encontrando-se com seus pares esporadicamente.

Além desse aspecto, por ser a única escola que oferta turmas do Ensino Médio e ser da rede estadual, os educadores que ministram aulas nesta instituição escolar também ensinam em outras escolas da rede municipal da região, para complementar e/ou completar sua carga horária, de 30 (trinta) ou 40 (quarenta) horas semanais, entre as duas redes de ensino, a estadual e 
a municipal, com modelos de trabalho diferenciados e burocracia própria. Conforme o Projeto Sala de Educador 2015 da Escola:

... a Escola Estadual 12 de Outubro torna-se uma instituição pública de ensino preparada, para "responder" aos desafios e paradigmas do mundo pós-moderno, tendo como meta o desenvolvimento de seus alunos, a ampliação das capacidades cognitivas e empíricas: informar, orientar e mediar a formação integral do aluno. Buscar ainda, a garantia de perfeita dinamização do Sistema Escolar, colocando em prática as disposições legais da Educação do Campo em consonância com as condições políticas, sociais, econômicas e culturais das comunidades camponesas, contribuindo para a evolução da capacidade de interpretar, posicionar-se e assumir uma postura crítica diante da diversidade de situações que surgem no seu dia a dia. (PSE, 2015, p. 3).

Nesse contexto, a configuração existente na referida escola quanto à oferta do ensino médio na sede e fora dela, nas salas anexas, assim como os profissionais da educação serem ligados às duas redes de ensino - municipal e estadual - ensinarem em modalidades diferenciadas, traz para o trabalho docente e, consequentemente, para as práticas pedagógicas, uma complexidade característica da docência nas Escolas do Campo.

Além disso, é característico dessa região de Fronteira o fato da maioria dos profissionais que atuam não serem efetivos nas redes de ensino e possuírem contratos temporários. Assim, o quadro docente e técnico destas escolas é bastante rotativo, sendo um constante recomeço a formação continuada para esse quadro. Por conta disso, grande parte dos educadores não possuem suas residências fixas nas comunidades, passam a semana trabalhando entre as escolas das duas redes de ensino, sendo que, alguns fazem o trajeto diário de, em média, 180 quilômetros entre Cáceres e as Escolas para trabalhar ou outros, moram na comunidade durante a semana (segundas às sextas-feiras) e nos finais de semana voltam à cidade de Cáceres para suas famílias. Esse fato também influencia, e muito, o trabalho docente, pois poucos possuem uma identidade com a escola e com a formação nela desenvolvida.

Outra questão narrada pelos educadores e que representa outro desafio para o seu trabalho, é a existência de estudantes bolivianos que, por não falarem o português e, sim, o espanhol, trazem ao espaço escolar e para o trabalho docente significativo entrave, pois os docentes não sabem falar em espanhol e a comunicação fica bastante dificultada.

Desse modo, a estrutura do trabalho docente do campo e as realidades existentes na comunidade nos fazem 
concordar com Lima (2013, p. 57) quando reflete:

Reconhecer a realidade e as diferenças na Educação do Campo não significa inferiorizá-lo ou exaltála em relação às outras diversidades. Busca-se uma proposta de formação continuada e um projeto de escola, numa perspectiva dialética, abrangente que possa romper com a construção epistemológica corrente que nos induz a acreditar que existe uma dicotomia entre campo e cidade.

Com isso, somos movidos a refletir e a contribuir com as escolas do campo por meio de oficinas que sejam espaços de reflexão e ação, de encontro e troca de experiências para os profissionais da Educação do Campo. Esses espaços nos possibilitam, com os docentes do campo, reconhecer os desafios existentes nessas escolas para que, realmente, organizem-se a partir dos princípios da Educação do Campo, que perpassam pela configuração do quadro profissional enquanto aspectos de sua formação inicial e continuada, identidade e reconhecimento da comunidade na qual as escolas estão inseridas e as suas condições de trabalho docente.

Nesse contexto de reflexão, percebemos que o quadro encontrado nas escolas do Campo aproxima-se ao que Ramos, Moreira e Santos (2004, p. 7) apontam a partir de um diagnóstico da educação brasileira rural: a evolução da educação escolar brasileira nos deixou como herança um quadro de precariedade no funcionamento da escola do campo: em relação aos elementos humanos disponíveis para o trabalho pedagógico, a infraestrutura e os espaços físicos inadequados, as escolas mal distribuídas geograficamente, a falta de condições de trabalho, salários defasados, ausência de uma formação inicial e continuada adequada ao exercício docente no campo e uma organização curricular descontextualizada da vida dos povos do campo.

Essa constatação, elaborada pelas autoras no documento 'Referências para uma Política Nacional de Educação do Campo: Caderno de Subsídios', publicado em 2004, pela Secretaria de Educação Média e Tecnológica, no Grupo Permanente de Trabalho de Educação do Campo, constituído a partir do Diagnóstico da Educação Brasileira, aproxima-se bastante das reflexões que trazemos evidenciadas há mais de uma década após a publicação deste documento e que mostram a realidade do Estado de Mato Grosso e de uma região específica dele. Os Docentes e o seu trabalho na
Educação do Campo: o nosso olhar a
partir das narrativas

Segundo o PSE, de 2015, da Escola Estadual 12 de Outubro, "a formação continuada em serviço tem se apresentado como uma possibilidade de melhoria da 
qualidade da educação dentro do contexto educacional contemporâneo". (p.6). Assim, ela investe anualmente na elaboração colaborativa de uma formação continuada com temáticas escolhidas pela comunidade educativa, considerando importante proporcionar "vez $e$ voz aos profissionais da educação da unidade escolar e a devida importância ao contexto camponês visando à compreensão da ação formativa ou educativa". (PSE, 2015, p. 6 - grifo original). Pois reconhecem que a: “... escola de espaço ensino-aprendizagem, concentrado na sala de aula, passou a ser espaço educativo, com múltiplas tarefas, várias delas confiadas não somente aos professores, mas a outros funcionários". (Moraes, 2009, p. 400).

Por essa razão, a formação continuada é oferecida para todos aqueles que na escola desenvolvem o ato educativo, dentro ou fora da sala de aula, no espaço escola ou na comunidade, com a proposição de integração entre os sujeitos. Assim, conhecer quem são os profissionais da educação da Escola Estadual 12 de Outubro, mais especificamente os docentes, quanto aos aspectos formação, tempo de serviço, número de escolas que trabalham na região e disciplinas que ensinam, trouxe-nos entendimento sobre a configuração do trabalho docente nesta escolav .

$\mathrm{Na}$ oficina estavam presentes 40 (quarenta) profissionais na educação, conforme as funções mencionadas no quadro a seguir:

Quadro 2 - Profissionais da Educação do Campo presentes na Oficina.

\begin{tabular}{|l|c|c|c|}
\hline $\begin{array}{c}\text { Função que } \\
\text { desempenha na } \\
\text { Escola 12 de Outubro }\end{array}$ & $\begin{array}{c}\text { Quantidade presentes na } \\
\text { Oficina }\end{array}$ & $\begin{array}{c}\text { Total de Funcionários da } \\
\text { Escola distribuídos por } \\
\text { funções }^{\mathbf{v i}}\end{array}$ & $\begin{array}{c}\text { Porcentagem de } \\
\text { Presença }\end{array}$ \\
\hline Professores & 28 & 30 & $93,3 \%$ \\
\hline Técnico Administrativo & 01 & & \\
\cline { 1 - 2 } Técnico de Apoio & 04 & 17 & $70,6 \%$ \\
\cline { 1 - 2 } Técnico da Nutrição & 04 & & $85,1 \%$ \\
\hline Guarda & 02 & & \\
\cline { 1 - 2 } Motorista TOTAL & 01 & 47 & \\
\hline
\end{tabular}

(Fonte: Lista de Presença da Oficina).

A partir do quadro 2, podemos perceber que a adesão e presença na formação continuada, no dia em que realizamos tal oficina, foi boa, representando $85,1 \%$ total de profissionais da escola, distribuídos entre professores/docentes e técnicos administrativos educacionais (TAE). Além 
disso, observa-se que entre as duas categorias houve uma maior adesão dos professores, tendo a presença de $93,3 \%$ do total dos professores lotados nesta escola.

Com toda essa presença e, justamente, por ser composta por profissionais que desempenham diferentes funções na escola, ministrou-se a Oficina de modo que todos os profissionais se percebessem parte do fazer pedagógico, a partir das funções que desenvolvem.

Iniciamos a formação recuperando o objetivo que a escola tem para a formação dos jovens e adultos que cursam o Ensino Médio e a EJA. Trouxemos do PPP (2014) da escola esse objetivo, e compartilhamos com o grupo, problematizamos, levando-os a refletir sobre o que cada um, a partir da sua função na escola, faz para que o coletivo alcance o objetivo da formação das crianças, jovens e adultos, presente neste projeto. A reação inicial foi de silenciamento e de troca de olhares. Não esperávamos essa reação e, sim, a narrativa do que estão discutindo no coletivo do que cada um(a), em suas diferentes funções, desenvolvem para fazer da Escola Estadual 12 de Outubro uma escola de Ensino Médio e do Campo, pois planejamos essa dinâmica a partir do que já conhecíamos, fruto de ações anteriores de pesquisa e extensão e, também, a partir dos documentos fornecidos pela escola.
Como nenhuma voz era ouvida, questionamos sobre o planejamento de ensino dos professores, os projetos desenvolvidos, as práticas pedagógicas, seu trabalho cotidiano, o dia a dia da escola e deles enquanto profissionais da educação e sua relação com o PPP da instituição. Depois de alguns minutos, um professor narrou: "fazemos o planejamento no início do ano e lá olhamos o PPP da escola, porém, não é uma prática cotidiana discutirmos juntos o que cada um vai fazer nas disciplinas que cada um de nós dá aula. Cada um faz o seu planejamento para suas disciplinas. Não temos tempo para nos encontrarmos e fazer trocas ... Nossas trocas são feitas em momentos como esse e esses momentos são poucos" (Fala de um Professor - registrada em Vídeo).

Essa narrativa denota a escassez de tempo para o conhecimento dos pares, para o planejamento coletivo, para as trocas de experiências tão importantes ao trabalho docente, visto que

Marx, contudo, mostrou que o processo do trabalho transforma dialeticamente não apenas o objeto, mas igualmente o trabalhador, bem como suas condições de trabalho. Trabalhar não é exclusivamente transformar um objeto em alguma outra coisa, em outro objeto, mas é envolver-se ao mesmo tempo numa práxis fundamental em que o trabalhador também é transformado por seu trabalho. (Tardif \& Lessard, 2005, p. 12). 
O trabalho é a docência, que tem como objeto de trabalho um outro ser humano, assim sendo, a interação entre os pares, o encontro entre os sujeitos escolares, as trocas, as reflexões e o pensar escola juntos os transforma e os identifica como profissionais da escola do campo, pois cada profissional da educação,

... está situado como sujeito que (re)constrói sua ação profissional, desenvolvendo, na vivência do cotidiano da sala de aula, conhecimentos relativos a seu ofício, aprendendo a fazer-se professor (a) na militância docente, vivendo, pois, os conflitos e desafios postos pelo fazer pedagógico. Os (as) professores (as) são profissionais que organizam, no cotidiano de seu trabalho, diferentes ações para responder às complexas demandas da prática pedagógica. (Brito, 2007, p. 54).

Considerando a narrativa do professor e a reflexão de Brito (2007), na oficina sentimos a necessidade de demonstrar que conhecíamos a realidade daquela escola, a partir dos sujeitos que a compõem. Dessa forma, poderíamos evidenciar a importância de considerar a organização da escola e seus trabalhadores e o que estes fazem para melhorar a qualidade das práticas pedagógicas na Educação do Campo, visto que eles afirmam que a Escola Estadual 12 de Outubro é uma escola que segue os princípios dessa modalidade de ensino.
Nesse sentido, concordamos com Caldart (2003, p. 5) quando reflete:

... para fazer uma escola do campo é preciso olhar para as ações ou práticas sociais que são constituídas dos sujeitos do campo. É preciso olhar para o movimento social do campo como um sujeito educativo, e aprender com os processos de formação humana que estão produzindo os novos trabalhadores $\mathrm{e}$ lutadores dos povos do campo, lições que nos ajudem a pensar um outro tipo de escola para eles, com eles.

A autora citada recupera a reflexão das Diretrizes Operacionais da Educação do Campo quando menciona: "O campo, nesse sentido, mais do que um perímetro não urbano, é um campo de possibilidades que dinamizam a ligação dos seres humanos com a própria produção das condições da existência social e com as realizações da sociedade humana". (Brasil, 2001, p. 1). Necessita, assim, de um currículo adequado e contextualizado com a realidade local, que respeite os sujeitos do campo e os possibilitem ser protagonistas da sua formação e vida. Para que isso aconteça, é importante ter professores que conheçam essa realidade do campo, que vivam nela e, nela e por ela, queiram trabalhar.

Sendo assim, apresentamos aos participantes da entrevista o que chamamos de diagnóstico, feito a partir de dados fornecidos pela escola, que nos permitiu verificar a distribuição dos docentes nos 
diferentes espaços onde a Escola Estadual 12 de Outubro fornece Ensino Médio e a EJA e solicitamos que eles descrevessem seu trabalho cotidiano nestes diferentes espaços, como mostramos na Figura 1 a seguir:

Figura 1 - O Ensino Médio na Região de Fronteira: distribuição dos Docentes por salas anexas/Sede.

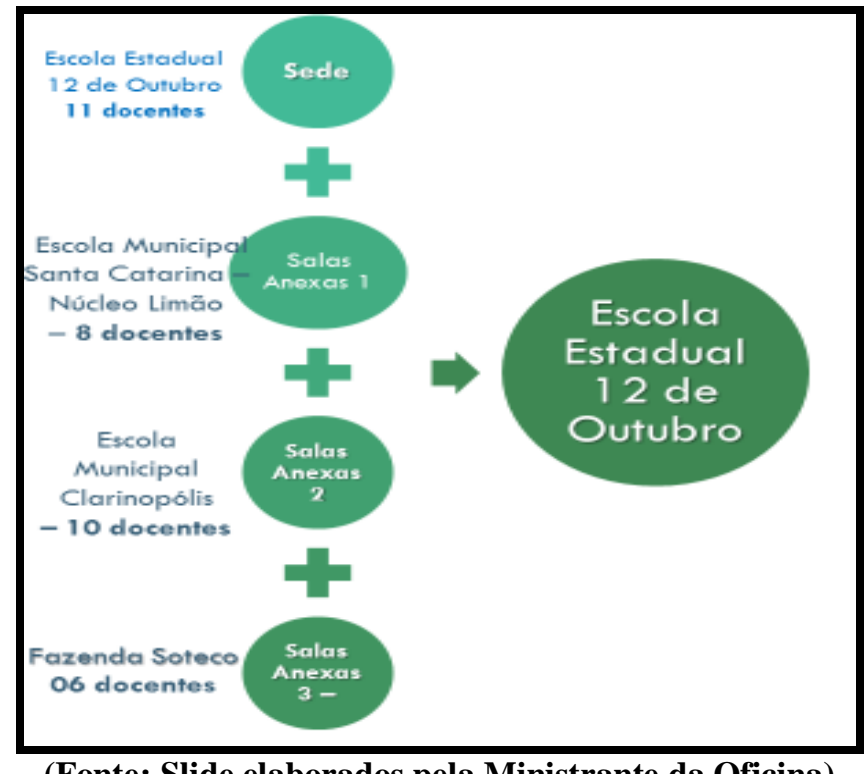

(Fonte: Slide elaborados pela Ministrante da Oficina)

A figura 1, elaborada a partir dos dados fornecidos pela Escola, em Março de 2015, dias antes da oficina, mostra a distribuição dos docentes nos diferentes espaços onde é ofertado o Ensino Médio e EJA. Com essa distribuição percebemos o quanto é complexo fazer Educação do Campo e desenvolver o Ensino Médio na região de Fronteira Brasil-Bolívia, sem deixar de respeitar o local de moradia dos alunos.

O quadro docente da Escola Estadual 12 de Outubro é composto por um total de 30 (trinta) professores, o que significa que alguns deles trabalham em mais de uma localidade em diferentes salas anexas de
Ensino Médio. Segundo a descrição dos professores, isso acontece pela carga horária das disciplinas em que atuam, por exemplo, o professor graduado em Educação Física, segundo ele e os documentos fornecidos pela escola, ministra aulas da disciplina nas quatro localidades para completar a carga horária de seu contrato de trabalho: "essa situação de trabalhar em diferentes locais, as distâncias que tenho que percorrer $e$ o tempo escasso para planejar, influencia e muito no meu fazer docente." (Fala de um Professor - registrada em Vídeo).

Além das precárias condições de planejamento, encontros entre os pares, 
formação adequada, ainda cabe salientar que a maioria dos profissionais da educação desta escola, tanto os técnicos como os professores, não são efetivos na rede Estadual de ensino e, sim, contratados. Os que são efetivos (minoria) estão na instituição por não terem conseguido aulas em escolas da zona urbana do município de Cáceres. À primeira chance de vaga na cidade, optam por ministrar aulas na zona urbana.

Conforme os mesmos dados fornecidos pela escola, temos a seguinte distribuição por localidade e número de locais trabalhados pelo mesmo docente, sistematizados no quadro a seguir:

Quadro 3 - Quantidade de Docentes por localidades/Escola que atuam.

\begin{tabular}{|c|c|}
\hline $\begin{array}{c}\text { Quantidade de localidades em que os } \\
\text { Professores realizam o seu trabalho }\end{array}$ & Número de Professores nesta situação \\
\hline 04 localidades (Sede e/ou 03 Salas Anexas) & 01 \\
\hline 03 localidades (Sede e/ou 03 Salas Anexas) & 00 \\
\hline 02 localidades (Sede e/ou 03 Salas Anexas) & 08 \\
\hline 01 localidades (Sede e/ou 03 Salas Anexas) & 19 \\
\hline
\end{tabular}

(Fonte: Dados fornecidos pela Escola Estadual 12 de Outubro - Março de 2015).

$\mathrm{Na}$ primeira coluna do quadro 3, mostramos a quantidade de localidades nas quais os professores atuam, podendo variar entre 01 (uma) a 04 (quatro) localidades. Esse quadro foi projetado como parte do diagnóstico elaborado e solicitamos aos profissionais da educação presentes na oficina que identificassem em que situação se enquadravam e as relatassem, considerando as suas condições de trabalho docente cotidianas nestes diferentes espaços, nos permitindo compreender o que é ser docente da Educação do Campo.

Observa-se um número expressivo de docentes que atuam no Ensino Médio em duas localidades diferentes, sendo, na maioria delas, na Sede da Escola 12 de Outubro e na Escola Municipal Santa Catarina, na Comunidade do Limão, distantes, aproximadamente, quilômetros uma da outra. Esses mesmos profissionais também completam a sua carga horária semanal com aulas no Ensino Fundamental nas escolas da rede municipal. Notamos a predominância de profissionais, 19 (dezenove) deles, que trabalham em uma única localidade e, nesses casos, se distribuem como mostramos a seguir: 
Quadro 4 - Quantidade de Docentes que atuam no Ensino Médio ou EJA em uma única localidade.

\begin{tabular}{|c|c|}
\hline Localidades & $\begin{array}{c}\text { Número de Professores nesta } \\
\text { situação }\end{array}$ \\
\hline Sede - Escola Estadual 12 de Outubro & 02 \\
\hline Salas Anexas 1 - Escola Municipal Santa Catarina & 01 \\
\hline Salas Anexas 2 - Escola Municipal Clarinópolis & 09 \\
\hline Salas Anexas 3 - Fazenda Soteco & 07 \\
\hline TOTAL & $\mathbf{1 9}$ \\
\hline
\end{tabular}

(Fonte: Dados fornecidos pela Escola Estadual 12 de Outubro- Março de 2015).

É possível observar no quadro acima, que existe um número grande de docentes atuando somente na Escola Municipal Clarinópolis ou na Escola da Fazenda Soteco, pois as duas escolas têm um maior distanciamento em relação à escola sede. Temos que destacar, no entanto, que eles, além de atuarem no Ensino Médio, também atuam no Ensino Fundamental em
Escolas da Rede Municipal, o que inclusive influencia bastante em seu trabalho docente, visto que, por serem redes de ensino diferentes, possuem orientações distintas, outra forma de organização do trabalho, com outra estrutura de registros e etc., como podemos observar na Figura 2, a seguir:

Figura 2 - As Escolas, Redes de Ensino e suas diferenças - configuração das práticas

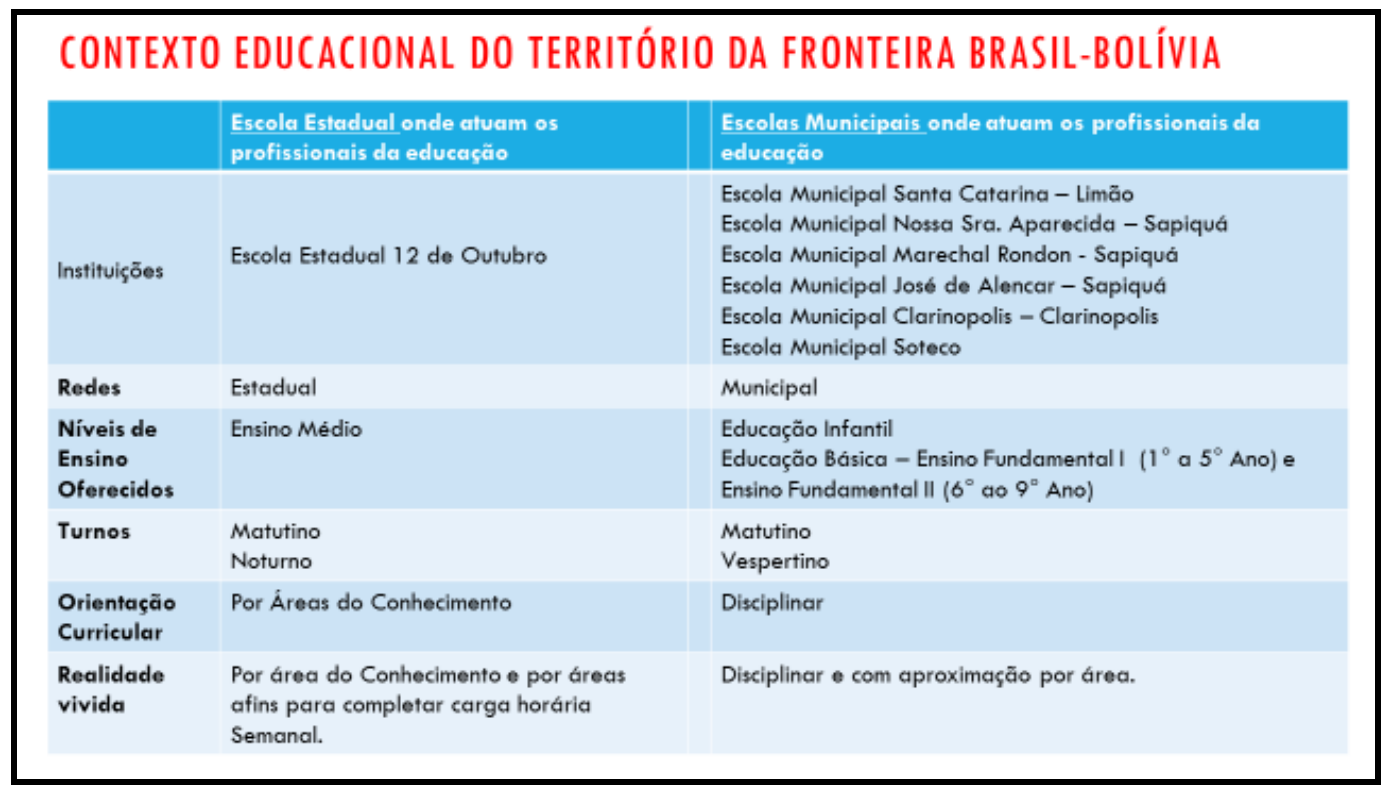

(Fonte: Slide elaborado pela Ministrante da Oficina).

Nesta figura, mostramos o contexto educacional da região de fronteira Brasil-
Bolívia composto em duas redes de ensino, a Estadual e a Municipal, destacando que 
da rede estadual só a Escola Estadual 12 de Outubro oferece o Ensino Médio e EJA, com orientação curricular por áreas do conhecimento, em que a atribuição de aulas respeita a lógica das áreas do conhecimento. Já a rede municipal, oferta a Educação Infantil, Educação Básica, mais especificamente, Ensino Fundamental I ( ${ }^{\circ}$ ao $5^{\circ}$ ano) e Ensino Fundamental II ( $6^{\circ}$ ao $9^{\circ}$ ano), segue uma orientação curricular disciplinar e atribui aulas para os professores formados por disciplinas.

Quanto à formação dos docentes da Escola Estadual 12 de Outubro, enquanto graduação percebemos que a realidade se agrava um pouco, pois para completar a carga horária semanal de aula na rede estadual, portanto, no Ensino Médio e EJA, o profissional que faz a sua formação inicial por especificidades, por exemplo, em Educação

Física, Letras/Literatura/Língua Estrangeira, Geografia, História e Matemática, submete-se a assumir aulas para além de sua formação.

Segundo o relato dos professores a atribuição de aula no Estado é feita por área do Conhecimento, permitindo que o professor formado em Geografia, por exemplo, trabalhe também com Sociologia, Filosofia e História, porque todas essas disciplinas fazem parte de uma mesma área do conhecimento. Como se pode observar no quadro 5, a seguir:

Quadro 5 - Configuração do trabalho docente por área do conhecimento e disciplinas.

\begin{tabular}{|c|c|c|c|c|}
\hline $\begin{array}{l}\text { Especificidade } \\
\text { disciplinar da } \\
\text { Graduação em: }\end{array}$ & $\begin{array}{c}\text { Área do } \\
\text { Conhecimento: }\end{array}$ & $\begin{array}{c}\text { Quantidade de } \\
\text { Professores } \\
\text { Formados }\end{array}$ & $\begin{array}{l}\text { Disciplinas que } \\
\text { ministram aulas: }\end{array}$ & $\begin{array}{l}\text { Quantidade de } \\
\text { Professores que } \\
\text { ministram a } \\
\text { disciplina }\end{array}$ \\
\hline Educação Física & Linguagem & 01 & Educação Física & 01 \\
\hline \multirow{4}{*}{ Letras } & \multirow{4}{*}{ Linguagem } & \multirow{4}{*}{06} & Língua Portuguesa & 05 \\
\hline & & & Inglês & 05 \\
\hline & & & Espanhol & 03 \\
\hline & & & Artes & 04 \\
\hline \multirow{3}{*}{$\begin{array}{l}\text { Ciência } \\
\text { Biológicas }\end{array}$} & \multirow{3}{*}{$\begin{array}{c}\text { Ciência da Natureza } \\
\text { e da Terra }\end{array}$} & \multirow{3}{*}{03} & Biologia & 02 \\
\hline & & & Química & 02 \\
\hline & & & Física & 01 \\
\hline \multirow{3}{*}{ História } & \multirow{3}{*}{ Ciências Humanas } & \multirow{3}{*}{05} & História & 05 \\
\hline & & & Sociologia & 03 \\
\hline & & & Filosofia & 04 \\
\hline \multirow{7}{*}{ Geografia } & \multirow{7}{*}{ Ciências Humanas } & \multirow{7}{*}{05} & Geografia & 04 \\
\hline & & & Sociologia & 03 \\
\hline & & & Filosofia & 02 \\
\hline & & & Artes & 01 \\
\hline & & & Língua Portuguesa & 01 \\
\hline & & & Língua Inglesa & 01 \\
\hline & & & Biologia & 01 \\
\hline
\end{tabular}




\begin{tabular}{|c|c|c|c|c|}
\hline & & & História & 02 \\
\hline \multirow{3}{*}{ Matemática } & \multirow{3}{*}{ Ciências Exatas } & \multirow{2}{*}{05} & Matemática & 05 \\
\cline { 3 - 5 } & & & Física & 04 \\
\cline { 3 - 5 } & & & Química & 03 \\
\hline Pedagogia & Ciências Humanas & 03 & Ensino Global & 03 \\
\hline \multicolumn{2}{|c|}{ TOTAL } & $\mathbf{2 8}$ & & \\
\hline
\end{tabular}

(Fonte: Dados fornecidos pela Escola Estadual 12 de Outubro - Março de 2015).

Como visualizamos no quadro anterior, entre os docentes que cursavam a oficina, não havia ninguém formado em Filosofia, Sociologia, Química e Física, levando os professores formados em áreas afins a assumirem as aulas dessas disciplinas curriculares. Tudo que foi refletido neste artigo nos aproxima do que Ramos, Moreira e Santos (2004) mencionam sobre a situação dos docentes nas escolas da zona rural brasileira:

\begin{abstract}
A literatura tem mostrado a importância destacada do professor no processo de progressão e aprendizado dos alunos. Apesar dessa constatação, a condição de trabalho desses profissionais tem-se deteriorado cada vez mais. No caso específico da área rural, além da baixa qualificação e salários inferiores aos da zona urbana, eles enfrentam, entre outras, as questões de sobrecarga de trabalho, alta rotatividade e dificuldades de acesso à escola, em função das condições das estradas e da falta de ajuda de custo para locomoção. (p. 27).
\end{abstract}

Em síntese, evidenciamos as condições precárias de trabalho dos docentes da escola considerada, destacando que vivem em condições de trabalho muito deterioradas, deslocam-se entre uma escola e outra para trabalhar, servem a redes de ensino diferentes, que não dialogam e propõem, inclusive, espaços de formação continuada diferentes e em momentos diferentes.

Ademais cabe refletir que estes professores, na formação inicial que desenvolveram, pouco são preparados para atuar na Educação do Campo, ou pelo menos trataram ou refletiram sobre a Educação do Campo de algum modo no currículo dos cursos de licenciaturas. Ainda em relação à formação inicial, são formados por especifidades, no entanto, ao trabalharem na Educação do Campo, assumem disciplinas para além de sua formação, pela necessidade de complementarem com cargas horárias de outras áreas. Tais apontamentos poderão ser observados na discussão que trazemos a seguir.

\section{As narrativas sobre o seu trabalho docente}

Neste espaço aprofundaremos a análise sobre o que os professores escreveram acerca de seus trabalhos cotidianos em uma atividade proposta a 
eles. Nossa análise terá como universo as narrativas de 28 docentes e traremos as vozes desses sujeitos que integram as práticas pedagógicas no/do campo, como afirmam Oliveira e Geraldi (2010, p. 23):

Precisamos de narrativas que contribuam para a compreensão ampliada do que é e do que pode ser a realidade social na qual estamos vivendo, escamoteada e tornada invisível 'a olho nu' pelas normas e regulamentos da cientificidade moderna, da hierarquia que esta estabelece entre teoria e prática e dos textos produzidos segundo o seu ditame.

A partir das narrativas, identificamos como categorias para compreender o trabalho docente: (1) o planejamento e as (2) condições de trabalho pedagógico, levando em consideração a formação dos docentes e as disciplinas em que atuam.

Ao narrarem seu trabalho docente cotidiano indicam como dificuldade o fato da maioria morar na zona urbana e trabalhar na zona rural, deslocando-se para a escola diariamente ou no primeiro dia letivo da semana (segunda-feira) e retornando para sua residência na sextafeira. Este fragmento exemplifica o descrito pelos professores: "Para trabalhar, diariamente me desloco de moto e vou da zona urbana para a zona rural, saio às 05 horas da manhã e durante o deslocamento encontro várias dificuldades, só vou citar como exemplo: chuva, frio, animais na pista, etc. ..." (Prof. 5 - Formado em História - trabalha com Sociologia, História e Filosofia)

Entre os professores a maioria faz diariamente o descrito pelo Prof. 5 e em suas narrativas destacam que essa situação dificulta muito as práticas pedagógicas, pois já chegam na escola cansados. Outra situação semelhante, que também é identificada por eles, é o deslocamento dos alunos: “... temos diariamente vários problemas como atraso do ônibus que traz os alunos para estudar, alguns alunos adultos que vêm bêbados para a escola $e$ outros tantos problemas que afetam no nosso dia a dia”. (Prof. 3 - Formado em Letras). Nesse fragmento, o professor refere-se ao período noturno, no qual é ofertada pela escola turmas da Educação de Jovens e Adultos (EJA) em que o público é de jovens e adultos que, comumente, trabalham o dia inteiro e vêm estudar já cansados. Assim, é necessário que o professor tenha paciência e sabedoria para lidar com todas as situações que lhe são apresentadas, conciliando a realidade de seu público com o planejamento, pois segundo Saviani (2007), a relação entre o trabalho e a educação é implícita e indireta. Nela, o domínio da leitura e da escrita, da matemática e dos princípios das ciências naturais e sociais significa a compreensão do mundo em que se vive e, ao mesmo 
tempo, o entendimento da própria produção dos conhecimentos nas relações do trabalho produtivo, no interior da sociedade.

Ao narrarem sobre suas práticas pedagógicas explicitam como o planejamento é realizado: “... Não é tarefa fácil fazer planejamentos para todas as modalidades de aprendizado, mas tenho que me desdobrar diante de tudo que me envolve enquanto professor do município e Estado na área de ciências humanas ... o tempo é curto, mas tento dar o melhor para nossos alunos. ... ainda tem as salas multisseriadas que acabam sendo um trabalho mais árduo, pois preciso de mais atenção; observação, acompanhamento constante; em que as explicações do conteúdo ficam mais curtos por motivos de tempo: onde existem alunos de todas as séries e todos níveis de aprendizado". (Prof. 1 - Formado em História Trabalha com História, Sociologia e Filosofia). Assim como o Prof. 1, os professores destacam a dificuldade de trabalhar nas duas redes de ensino, ou seja, na rede municipal em escolas municipais da região e na rede estadual, no caso, Escola Estadual 12 de Outubro. Para eles isso significa cumprir as normas de cada rede em relação ao tipo de planejamento, diários, relatórios, formação continuada e etc., intensificando ainda mais as suas práticas pedagógicas, pois necessitam respeitar as especifidades de cada rede de ensino e, também, dos sujeitos enquanto níveis diferentes de aprendizado. Outra situação exposta pelo Prof. 1 é que as salas multisseriadas intensificam a exigência do trabalho, como pode ser observado neste trecho: "...cheguei na comunidade [de Clarinópolis] no ano de 2009, um trabalho pelo município. No meu primeiro ano em Clarinópolis enfrentei uma sala multisseriada com quatro turmas diferentes na mesma sala. Eu e o professor ... dividíamos as turmas. As minhas disciplinas eram geografia, língua portuguesa e língua Inglesa”. (Prof. 3 Formado em Letras - trabalha com Língua Portuguesa, Inglês, Artes). Desse modo, evidencia-se a precariedade das condições de trabalho docente, sendo complexo planejar aulas para turmas multisseriadas, haja vista as diversidades existentes, tendo o tempo de aula e de dedicação aos conteúdos de cada série reduzidos.

Além disso, narram, enquanto intensificador das suas práticas, as condições de trabalho que nem sempre são as ideais, como se observa a seguir: " $A$ Escola de Clarinópolis é bem estruturada com relação às outras escolas da zona rural, eu leciono, no período matutino e o plano de aula eu faço de acordo com as dificuldades apresentada pelos alunos. 
Utilizo livros e como recursos didáticos utilizo data show, mapa e globo. Já na Escola Estadual 12 de Outubro, sala extensão no Limão, a dificuldade ainda é maior ... por causa da insalubridade com salas improvisadas em um antigo posto de saúde que está desativado sem forro e com divisórias de madeira, o plano de aula é difícil seguir, só utilizo livros didáticos mesmo e ainda desatualizados. Às aulas começam às 11:30 até às 16:30hs por causa da distância que os alunos moram”. (Prof. 4 - Formado em Geografia trabalha com Geografia). Tal ocorrência também é evidenciada na próxima narrativa: "Na verdade, não temos condições dignas de trabalho nas salas do Limão. Dar aula naquele lugar é difícil, as salas são quentes, pequenas e existe nelas bichos como morcegos, porcos e vacas. Às vezes, os professores precisam dar aula fora da sala”. (Prof. 3).

Observar-se nas narrativas que nenhum dos docentes questiona e leva em consideração qual educação que os povos do campo necessita. Referem-se às práticas que desenvolvem e às adaptações que fazem em relação ao público que frequenta aquela escola, mas não refletem sobre as Escolas em que atuam serem escolas do Campo. Só o fazem ao se referir-se a distância e às condições péssimas de trabalho.

\section{Considerações Finais}

Nossa aproximação com as escolas da região da fronteira Brasil-Bolívia, denominadas pelo poder público municipal e estadual como escolas do campo, fazemnos refletir sobre a precariedade do entendimento do poder público do que é uma escola do campo, ou pelo menos, do que deveria ser uma escola para os sujeitos que residem em uma região localizada na zona rural de um município.

A escola pesquisada é uma escola relativamente nova, com instalações e infraestrutura boas, se comparada às escolas municipais da mesma região, porém, com um quadro docente que oscila muito de mês para mês. Assim, as discussões sobre Educação do Campo estão sempre recomeçando, sendo um assunto desconhecido para alguns, fazendo-nos refletir que a falta de conhecimento sobre a Educação do Campo, sobre a necessidade de um currículo que garanta a identidade dos sujeitos, que evidencie os conteúdos próprios e contextualizados da vida e do bem viver para aqueles sujeitos, impulsiona os docentes a reproduzirem as mesmas práticas pedagógicas das escolas da zona urbana.

A partir da Oficina desenvolvida tivemos condições de compreender as configurações do trabalho docente naquela 
localidade, a partir das vozes dos próprios docentes. Impressionou-nos todas as dificuldades que encontram diariamente, a necessidade de assumir disciplinas que, nem sempre, estão preparados para ensinar, porém por falta de docentes com determinada formação, assumem e procuram fazer da melhor forma possível, estudando os conteúdos, aprendendo primeiro para, então, ensinar aos alunos.

Outra situação que ficou bastante evidente foi a falta de Livro Didático de acordo com o número de alunos, sendo identificada por eles como uma dificuldade para o trabalho pedagógico.

Nesta Oficina, os docentes dialogaram e chegaram à conclusão da necessidade de participar da formação continuada e utilizá-la como espaço para planejar as ações a serem desenvolvidas na escola de forma colaborativa com todos os sujeitos escolares, trazendo-nos esperança e força para continuar nossa militância pela Educação do Campo com qualidade para todos.

\section{Referências}

Brasil. Ministério da Educação. (2001). Conselho Nacional de Educação. Diretrizes Operacionais para a Educação Básica nas Escolas do Campo. Parecer $n^{\circ}$ 36/2001. Brasília.

Brito, A. E. (2007). Sobre a Formação e a Prática Pedagógica: o saber, o saber-ser e o saber-fazer no exercício profissional. In
Mendes Sobrinho, J. A. C. Formação $e$ Prática pedagógica: diferentes contextos de análise. Teresina: EDUFPI.

Caldart, R. S. (2003). A Escola do Campo em Movimento. Currículo sem Fronteiras, 3(1), 60-81.

Fiorentini, D., \& Lorenzato, S. (2012). Investigação em Educação Matemática: Percursos Teóricos e Metodológicos. Campinas, SP: Autores Associados.

Gaia, C., \& Pires, L. S. (2016). Saberes matemáticos e história de vida na zona rural de Marabá-PA. Rev. Bras. Educ. Camp., 1(1), 128-146.

Lima, R. F. (2013). Formação de professores da Escola do Campo em Cáceres-MT: identidade em construção. (Dissertação de Mestrado). Universidade de Estado de Mato Grosso.

Moraes, J. V. M. (2009). A carreira e a gestão da escola: valorização e democracia. Revista semestral Retratos da Escola/CNTE, 3(5), 399 - 410.

Oliveira, I. B., \& Geraldi, J. W. (2010). Narrativas: outros conhecimentos, outras formas de expressão. In. Oliveira, I. B. (Org.). Narrativas: outros conhecimentos, outras formas de expressão. (p. 13-43). Petrópolis, RJ: DP Editora Ltda.

Projeto Político Pedagógico (PPP). (2014). Escola Estadual 12 de Outubro.

Projeto Sala de Educador (PSE). (2015). Escola Estadual 12 de Outubro. Projeto de Formação Continuada: Reflexão sobre a Prática Pedagógica.

Ramos, M. N., Moreira, T. M., \& Santos, C. A. (Coord.). (2004). Referências para uma política nacional de educação do campo: caderno de subsídios. Brasília: Secretaria de Educação Média e 
Tecnológica, Grupo Permanente de Trabalho de Educação do Campo.

Saviani, D. (2008). A pedagogia no Brasil: história e teoria. Campinas, SP: Autores Associado.

Silva, C. C. (2014). Formação Continuada: "A Sala de Educador" como espaço de Produção de Conhecimento

i O Projeto Sala de Educador é parte de uma política pública de formação continuada dos profissionais da educação [do Estado de Mato Grosso] no próprio local de trabalho, implantado e implementado no final do ano de 2003 nas escolas da rede estadual pela SEDUC/SUFP por intermédio dos CEFAPROs. (Silva, 2014, p. 68).

ii A Escola Estadual 12 de Outubro, com sede na BR 070, Km 70, situada na Agrovila, a $79 \mathrm{~km}$ do município de Cáceres, margem esquerda da BR 070 e a $290 \mathrm{~km}$ da capital Cuiabá - MT. Criada e autorizada pelo Conselho Estadual de Educação para atender a diversidade de Educação do Campo.

iii Conforme dados da página da SEDUC-MT, disponível

em:

www.seduc.mt.gov/Paginas/Unidades-

Escolares.aspx. Acesso em 20 de Jan. de 2017.

iv Conforme dados da página da SEDUC-MT, disponível em: http://www.seduc.mt.gov.br/Paginas/censo-escolarindicadores.aspx. Acesso em 20 de Jan. de 2017.

${ }^{v}$ Os dados analisados aqui foram fornecidos pela Escola Estadual 12 de Outubro por meio de um levantamento solicitado, assim como pela análise do Projeto Sala de Educador (PSE) de 2015 e o PPP de 2014. Também utilizamos as gravações em vídeo feitas durante a oficina citada e as anotações sobre as práticas pedagógicas dos docentes dessa escola.

vi Conforme dados da página da SEDUC-MT, disponível

em:

www.seduc.mt.gov/Paginas/Unidades-

Escolares.aspx. Acesso em 20 de Jan. de 2017.
(Dissertação de Mestrado). Universidade do Estado de Mato Grosso.

Tardif, M., \& Lessard, C. (2005). $O$ trabalho docente: elementos para uma teoria da docência como profissão de interações humanas. Petropólis, RJ. Editora Vozes.

Recebido em: 22/02/2017

Aprovado em: 13/03/2017

Publicado em: 19/04/2017

Como citar este artigo / How to cite this article / Como citar este artículo:

APA:

Bitencourt, L. P., \& Zart, L. L. (2017). Os educadores na educação do campo e as suas condições de trabalho docente. Rev. Bras. Educ. Camp., 2(1), 252274. DOI: http://dx.doi.org/10.20873/uft.2525$\underline{4863.2017 \mathrm{v} 2 \mathrm{n} 1 \mathrm{p} 252}$

ABNT:

BITENCOURT, L. P.; ZART, L. L. Os educadores na educação do campo e as suas condições de trabalho docente. Rev. Bras. Educ. Camp., Tocantinópolis, v. 2, n. 1, p. 252-274, 2017. DOI: http://dx.doi.org/10.20873/uft.2525$\underline{4863.2017 \mathrm{v} 2 \mathrm{n} 1 \mathrm{p} 252}$ 